ISSN 1112-9867

\title{
FRUITS AND VEGETABLES PREFERENCE AMONG UNIVERSITY STUDENTS TOWARDS DEVELOPING HEALTHY FOOD INNOVATION PRODUCTS
}

\author{
H. A. Mohd Abd Majid ${ }^{1 *}$, A. R. Abu Kassim ${ }^{1}$, K. Khalid ${ }^{1}$, J. Anuar ${ }^{1}$, N. F. Jusoh ${ }^{2}$, \\ N. F. S. Mohd Asri ${ }^{1}$, and S. N. S. Adnan ${ }^{1}$ \\ ${ }^{1}$ Faculty of Hotel and Tourism Management, Universiti Technologi MARA, 23000 Dungun, \\ Terengganu, Malaysia. \\ ${ }^{2}$ Nurtition Centre, Department of Health, 23000 Dungun, Terengganu, Malaysia
}

Published online: 17 October 2017

\begin{abstract}
Vegetables and fruits play an important role in student's healthy development. This study has two objectives which are i) to determine the preference of vegetables and fruitsand ii) to determine the awareness on healthy food innovation using fruits and vegetables among university students. 160 respondents were involved in this study and they were randomly selected from various faculties in Universiti Teknologi MARA, Dungun, Terengganu, Malaysia. The results show that $83.8 \%(n=134)$ of respondents has chosen fruits as their favourite while only $16.3 \%(n=26)$ reported for vegetables. In conclusion, this study has provided valuable information on fruit and vegetable preference among university student that may help in developing various food choices based on fruit and vegetable. This simultaneously can promote healthy lifestyle and healthy eating environment at university.
\end{abstract}

Keywords: fruits; vegetables; preference; university students

Author Correspondence, e-mail: hayati2959@tganu.uitm.edu.my doi: http://dx.doi.org/10.4314/jfas.v9i5s.72 


\section{INTRODUCTION}

\subsection{Background of the Study}

Food is essential in our life as it ensures our well-being. In the food pyramid, there are five food groups that are essential to be consumed in balanced amount i.e.: carbohydrate, protein, milk and dairy products, fruits and vegetables, salt, sugar and fat. Vegetables and fruits are low in calories and containno cholesterol. They are also a great source of fibre and an incredible source of vitamins and minerals. Moreover, vegetables and fruits also prevent chronic diseases as they have the necessary vitamins, minerals, and fibre for humans [1]. Besides, they also exist in different appealing colours like yellow, green, orange, red and white which are extremely valuable to humans since they contain potassium, folate, vitamin $\mathrm{C}$, and vitamin A [1]. The examples of fruits and vegetables which have an extensive variety of vital nutrients are sweet potatoes, yellow corn, green spinach, watermelon, and orange.

Other than that, fruits are naturally low in sodium, but the case might be different in canned fruits [1]. Canned products contain a lot of sodium as part of the preservatives. Thus, it is better for humans to consume fresh fruits. In addition, dried fruits such as raisins and apricots are also beneficial to humans because they contain iron which is needed by humans for efficient binding of oxygen to haemoglobin in the blood.

As the young consumers turn into adolescence, they may decide on their foods without restrictions based on their cravings and desires [2]. Typically, at the age of 18 or 19 years old, the majority of Malaysians enrol into higher education and start to live independently. Hence, when they enter the university, they are required to find and serve their foods on their own. Therefore, the adolescence's freedom and peers will influence their decisions on where, when and what they consume [3]. They will take more control of their way of life, mainly the food choiceand practices.

Fondness is the experience indicated by the level of dismay or delight towards particular nourishment and food. It is frequently mistaken with food preference which is leaning more towards expressing the food choice decision [4]. Besides that, there will be a few influencing factors that affect their food choices, for instance, the people who are close to them. In addition, the university students regularly obtain their foods from the markets or cafeteria around the university and this may affect their preferences. Nevertheless, it is bias to state that 
only these issues will affect the food choices of the university students. Moreover, with the provided information, it is expected that the knowledge and awareness of healthy food preference among young consumers can be enhanced theoretically and practically especially when they are deciding their food choices [2]. Thus, this study aims to determine the preference of vegetables and fruits among university students together with their awareness on fruit- and vegetable-based healthy food innovation.

\subsection{Problem Statement}

It is reported that many university students do not practice a healthy lifestyle [5]. Moreover, in numerous countries, the healthy eating habit has become an alarming concern because of the growth of overweight and obesity population in the world [6]. In a national survey conducted in 2011, it was found that $29.4 \%$ of Malaysians aged 18 years and above are overweight. Meanwhile, this study which was directed by the Institute for Public Health also found that $15.5 \%$ of Malaysians aged 18 years and above are in the obese class [7]. Therefore, this rising pattern of obesity among Malaysians gains the concern of the Ministry of Health. Other than that, based on the National Health Morbidity Survey conducted in 2015, it was found that obese individuals makes up $17.8 \%$ of the population while overweight individuals makes up $30.0 \%$ of the population [8]. Thus, this indicates that almost half of the 30 million Malaysian population is classified as overweight and obese which may lead to increasing occurrence of non-communicable disease (NCD) among Malaysians. Statistics also found that nearly $60.7 \%$ or more than 17 million Malaysians are facing NCD. Other than that, the data is predicted to rise in the future and the number of Malaysians with hypercholesterolemia, hypertension and diabetes are expecting to be 6.2 million, 5.8million and 2.6 million of the population respectively. Meanwhile, there might be numerous individuals who are undiagnosed of these diseases.

Furthermore, in most countries including Malaysia, the obesity rate is increasing due to the rising of living standard of Malaysians. It is alarming since obesity is the major contributor to many chronic diseases and disorders which affect individuals. Besides, too much or excessive consumptions of junk and unhealthy foods also undoubtedly lead to an unhealthy body. While the data represents the overall obesity rate among Malaysians, less is known about the obesity 
level among university students. This age group is considered an active group, but still contributes to the alarming increase of obesity in Malaysia.

Besides, based on the National Health and Morbidity Survey conducted in 2011, it was reported that 16.4 million or $92.5 \%$ of adults aged 18 years old and above consume small amounts of fruits and vegetables which is below five servings per day [7]. Low intake of fruits and vegetables is correlated to high risk of contracting the non-communicable diseases and having micronutrient deficiencies [9]. Therefore, the aim of this study is to determine the food preference of fruits and vegetables among university students. In addition, healthy food innovation awareness will be analyzed as well.

\section{METHODOLOGY}

\subsection{Type of Research and Research Design}

In this study, a quantitative research method was used and a descriptive method was applied. A descriptive method explains the features of things, individuals, groups, and the surroundings.

\subsection{Study Populations}

The respondents involved in this research are the students of Universiti Teknologi MARA Dungun Campus, Malaysia. Undergraduate students of different ages, genders and food choices based on food groups from various programs (such as Bachelor of Food Service, Bachelor of Finance and Bachelor of Hotel Management) were selected at random.

\subsection{Sample Size}

260 set of questionnaires were distributed, 160 respondents were involved in this research. $62 \%$ of response rate was accounted for this study. As stated by [19], 52.7\% response rate is the standard rate for research that assembles data from the public. There are some studies that also used a low response rate such as $55 \%$ by [20], 56\% by [21], and55.6\% by [22]. A probability sampling is applicable because it is required to gather the data by practicing simple random sampling. In simple random sampling, each respondent has a similar and standard probability of being selected as the research subject.

\subsection{Data collection}

To achieve the objectives of the study, a set of questionnaire had been constructed and 
distributed to all respondents. There are two sections in the questionnaire which are Section A and section B. Section A contains 11 questions on socio-demographic profile of the respondents. Meanwhile, section B is designated for fruit and vegetable preference questions. This questionnaire was adapted from [23] and Food Frequency Questions (FFQ) from NHANES (National Health and Nutrition Examination Survey). Malaysian Food Pyramid, 14 key messages and Malaysian Dietary Guidelines are used as the main guide in developing the questionnaire [11][24][25]. This questionnaire is constructed in the Malay language for good understanding and fast response, as well as preventing stress while answering the questionnaire. The questionnaire had been given to 30 respondents in a pilot study. During the pilot study, piloting assessment form had been distributed to determine the questionnaire's reliability and content analysis. A Cronbach's Alpha ranging from 0.62 to 0.7 was reported acceptable in the study [26].

In this study, the questionnaire was distributed to a focus group of respondents comprising of students studying in the class. The researcher handed in the questionnaire according to the suitability of the respondents in groups and the timing was arranged properly. The instructions and descriptions of the objectives of the study were described by the researcher. It was estimated that the respondents took between 15 to 30 minutes to answer the questionnaire, and the questionnaire was collected on the same day.

\subsection{Data analysis}

In this study, Statistical Package for the Social Sciences (SPSS) version 22.0 has been used to analyze the quantitative data. Then, all the results were presented through several charts and tables.

\section{RESULT AND DISCUSSION}

\subsection{Demographic}

Table 1 shows the demographic data of the respondents. There were 160 students involved in this study and they consisted of $87.5 \%(n=140)$ female and $12.5 \%(n=20)$ male. $83.7 \%$ of the respondents $(n=134)$ aged between 20 to 25 years while $16.3 \%$ of the respondents $(n=26)$ aged between 18 to 20 years. 
Table 1. Demographic data of respondents

\begin{tabular}{cccc}
\hline \multirow{2}{*}{ Gender } & & Frequency & Percentage (\%) \\
& Male & 20 & 12.5 \\
& Female & 140 & 87.5 \\
\multirow{2}{*}{ Age } & TOTAL & $\mathbf{1 6 0}$ & $\mathbf{1 0 0 . 0}$ \\
& 20-25 years old & 26 & 16.3 \\
& 18-20 years old & 134 & 83.7 \\
& TOTAL & $\mathbf{1 6 0}$ & $\mathbf{1 0 0 . 0}$ \\
\hline
\end{tabular}

\subsection{Preference of vegetables and fruits among the university students}

Comparing fruits and vegetables, this study demonstrates that fruits are more preferred by the respondents as compared to vegetables. Majority of the respondents, $83.8 \%(n=134)$ chose fruits as their preference while only a few respondents, $16.3 \%(n=26)$ chose vegetables. Fruits may have more advantages compared to vegetables in terms of their texture, taste, and appearance. Thus, this data encourages the development of fruit-based food innovation that may give more choices for healthy food product.

Table 2. Preference of vegetable and fruit groups

\begin{tabular}{ccc}
\hline & Frequency & Percentage (\%) \\
\hline Vegetables & 26 & 16.3 \\
Fruits & 134 & 83.8 \\
Total & $\mathbf{1 6 0}$ & $\mathbf{1 0 0 . 0}$ \\
\hline
\end{tabular}

As a major aspect of healthy lifestyle and diet, adequate consumption of vegetables and fruits is encouraged. Vegetables and fruits are a great and natural source of nutrients, making them important and fundamental for positive outcomes in the healthy diet regime. Besides, vegetables and fruits also help in the management of weight and decrease the risk of contracting various diseases and infections [10]. The previous study reported that consumption of vegetables and fruits lead to a healthy body, and as a prevention from critical chronic diseases like diabetes, hypertension, cancer and heart disease [4]. 


\subsubsection{Vegetables}

Table 3. Frequency and percentage of preference of vegetables

\begin{tabular}{cccc}
\hline & & Frequency & Percentage (\%) \\
\hline & Other (e.g.: long & 16 & 10.0 \\
& bean, broccoli etc.) & & \\
& Cabbage & 16 & 10.0 \\
Preference of & Cauliflowers & 27 & 16.9 \\
vegetables & Tomatoes & 29 & 18.1 \\
& Carrot & 30 & 18.8 \\
& Kangkung & 40 & 26.3 \\
& Total & 160 & 100.00 \\
\hline
\end{tabular}

Vegetables have different nutrients which are essential to human body. Table 3 demonstrates the most preferred vegetables in this study. It was found that kangkung is the most preferred vegetables with the percentage of $26.3 \%(n=40)$ of the total respondents. Other than that, a high percentage of respondents, $18.8 \%(n=30)$ preferred carrot followed by tomatoes with the percentage of $18.1 \%$ of the respondents $(n=29)$. Meanwhile, the less preferred vegetables were cabbage and other vegetables like long bean, cucumber, asparagus, celery and broccoli with the percentage of $10.0 \%(n=16)$ respectively.

Table 4. Frequency and percentage of preference cooking method of dishes/products

\begin{tabular}{cccc}
\hline & & Frequency & Percentage (\%) \\
\hline & Blanch & 2 & 1.2 \\
Preference of & Sauté & 4 & 2.5 \\
Cther (e.g.: & 15 & 9.4 \\
of & steam) & & \\
dishes/products & Boil & 21 & 13.1 \\
& Raw & 54 & 33.8 \\
& Frying & 64 & 40.0 \\
& Total & 160 & 100.00 \\
\hline
\end{tabular}


Table 4 shows the frequency and percentage of preference of cooking method of vegetable dishes. Based on Table 4, most of the respondents with the percentage of $40 \%(n=64)$ preferred frying method instead of other methods. The respondents preferred vegetable dishes like 'kangkung goreng belacan' (stir-fried kangkung with shrimp paste) and other vegetables which are prepared using the cooking method of frying. In addition, $33.8 \%(n=54)$ preferred to consume the vegetables such as salad, tomatoes, and 'ulaman-ulaman' (local salads) raw. Results also demonstrate that $13.1 \%(n=21)$ of the respondents preferred vegetables to be boiled like in the dishes 'sayur masak lemak' (vegetables cooked with coconut milk) and 'sayur masak air' (vegetables soup). Other than that, only $9.4 \%$ of the respondents $(n=15)$ chose vegetables prepared using other cooking methods like steaming or grilling. Meanwhile, only a small number of respondents chose blanching cooking method with the percentage of $1.2 \%(n=2)$. Vegetables can be prepared in various ways according to what is the best for the texture, look and taste of the vegetables. Malaysian Dietary Guidelines 2010 has recommended that some vegetables to be eaten raw and some to be cooked so that they are palatable and digestible. The vegetables can be mixed with eggs, fish, legumes, and meat [11].

Table 5. Frequency and percentage of preference of places to find products/dishes

\begin{tabular}{cccc}
\hline & & Frequency & Percentage (\%) \\
\hline & Convenience store & 3 & 1.9 \\
Preference of & Other (e.g.: fresh & 27 & 16.9 \\
places to & market) & & \\
obtain & Grocery store & 28 & 17.5 \\
products/dishes & Cafeteria & 44 & 27.5 \\
& Supermarkets & 58 & 36.3 \\
& Total & 160 & 100.00 \\
\hline
\end{tabular}

Table 5 indicates the frequency of respondents' preferences of places to findproducts or dishes. Results shows that $27.5 \%(\mathrm{n}=44)$ of university residents purchase vegetables at the cafeteria and $36.3 \%(\mathrm{n}=58)$ of non-residents buy their vegetables at supermarkets. It is found that more than half of the respondents prefer to find their products or dishes at supermarkets. It is well 
known that supermarkets serve vast choices ofproducts or dishes in many forms, i.e. canned, ready-prepared, etc.Results also showed that only a small number of the respondents $(1.9 \%$; $\mathrm{n}=3$ ) purchased vegetables which may be available in the forms of canned or ready-to-eat foods from the convenience store.

Table 6. Frequency and percentage of consumption of products/dishes

\begin{tabular}{|c|c|c|c|}
\hline & & Frequency & Percentage (\%) \\
\hline \multirow{7}{*}{$\begin{array}{l}\text { Frequency of } \\
\text { consumption of } \\
\text { products/dishes }\end{array}$} & $\begin{array}{c}4 \text { or more times per } \\
\text { day }\end{array}$ & 4 & 2.5 \\
\hline & 1 time per day & 12 & 7.5 \\
\hline & 2-3 times per day & 13 & 8.1 \\
\hline & 4 times per week & 26 & 16.3 \\
\hline & 1 time per week & 43 & 26.9 \\
\hline & 2-3 times per week & 62 & 38.8 \\
\hline & Total & 160 & 100.00 \\
\hline
\end{tabular}

Table 6 shows the frequency and percentage of consumption of products/dishes. It is also revealed that majority of the respondents $(38.3 \% ; n=62)$ consume vegetables 2 to 3 times a week. This study also found that $26.9 \%$ of the respondents consume vegetable products or dishes once a week while $16.3 \%(n=26)$ of them consume vegetables four times a week, as shown in Table 6. This results also reveal that only $8.1 \%(n=13)$ and $7.5 \%(n=12)$ of the respondents consume vegetable products or dishes 2 to 3 times and once a day respectively. The lack of vegetables consumption among the respondents may be due to several reasons such as the dishes are not palatable or attractive to the respondents and the vegetables are overcooked. In a study by Deliens et al. (2014), the students stated that the significant factor that influences their food preference is the taste of the food [12]. Taste can lead them to consume unhealthy food but also encourage them to consume healthy foods [12]. 


\subsubsection{Fruits}

Table 7. Frequency and percentage of preference of fruits

\begin{tabular}{cccc}
\hline & & Frequency & Percentage (\%) \\
\hline \multirow{2}{*}{$\begin{array}{c}\text { Papaya } \\
\text { Bruits }\end{array}$} & Orangana & 16 & 10.0 \\
& food) & 17 & 10.6 \\
& Watermelon & 41 & 10.6 \\
& Apple & 46 & 14.4 \\
& Total & 160 & 23.6 \\
& & & 28.8 \\
\hline
\end{tabular}

Table 7 reveals that apple is the most preferred fruit with the percentage of $28.8 \%(n=46)$ of the respondents. Then, it is followed by watermelon with a percentage of $25.6 \%(n=41)$. Other than that, $14.4 \%(n=23)$ of the respondents chose other fruits like rambutan, mangosteen, durian, guava, grapes, honeydew, and mango. Meanwhile, the least preferred fruit is papaya with the percentage of $10.0 \%(n=16)$ of the respondents.

Table 8. Frequency and percentage of preference of forms of fruit dishes/products

\begin{tabular}{cccc}
\hline & & Frequency & Percentage (\%) \\
\hline \multirow{2}{*}{ Preference of } & Other (e.g.: fruit jam) & 17 & 10.0 \\
forms of fruit & Fresh fruit & 17 & 10.6 \\
dishes/products & Fresh juice & 23 & 10.6 \\
& Total & 160 & 14.4 \\
& & & 100.00 \\
\hline
\end{tabular}

Table 8 shows the majority $(51.3 \% ; n=82)$ of the respondents chose to consume fruits in the form of juice. Then, the second highest choice is fresh fruit with the percentage of $33.1 \%$ $(n=53)$ while the least preferred $(7.5 \% ; n=12)$ form of fruits is desserts like cake and apple pie. It seems that more fresh fruit juice with less or no sugar can be developed based on their 
favorite and interest in future.

Table 9. Frequency and percentage of preference on places to find dishes/product

\begin{tabular}{cccc}
\hline & & Frequency & Percentage (\%) \\
\hline & Convenience store & 5 & 3.1 \\
Preference of & Grocery store & 21 & 13.1 \\
places to find & Other & 23 & 14.4 \\
products/dishes & Cafeteria & 37 & 23.1 \\
& Supermarkets & 74 & 46.3 \\
& Total & 160 & 100.00 \\
\hline
\end{tabular}

It is undeniable that supermarket is the best place for respondent to get their food and drink. Table 9 indicatesa majority $(46.3 \% ; n=74)$ of the respondents purchase fruits in supermarkets while $23.1 \%(n=37)$ of the respondents purchase fruits at cafeteria. This is followed by other places like petrol station and night market with $14.4 \%(n=23)$ of the respondents. Table 9 also indicates that only $3.1 \%(n=5)$ of the respondents get their fruits from the convenience store. Hence, from this findings it can be recommended that more fresh fruit can be sold at cafeteria to attract more respondent to consume fruits

Table 10. Frequency and percentage of consuming dishes/products

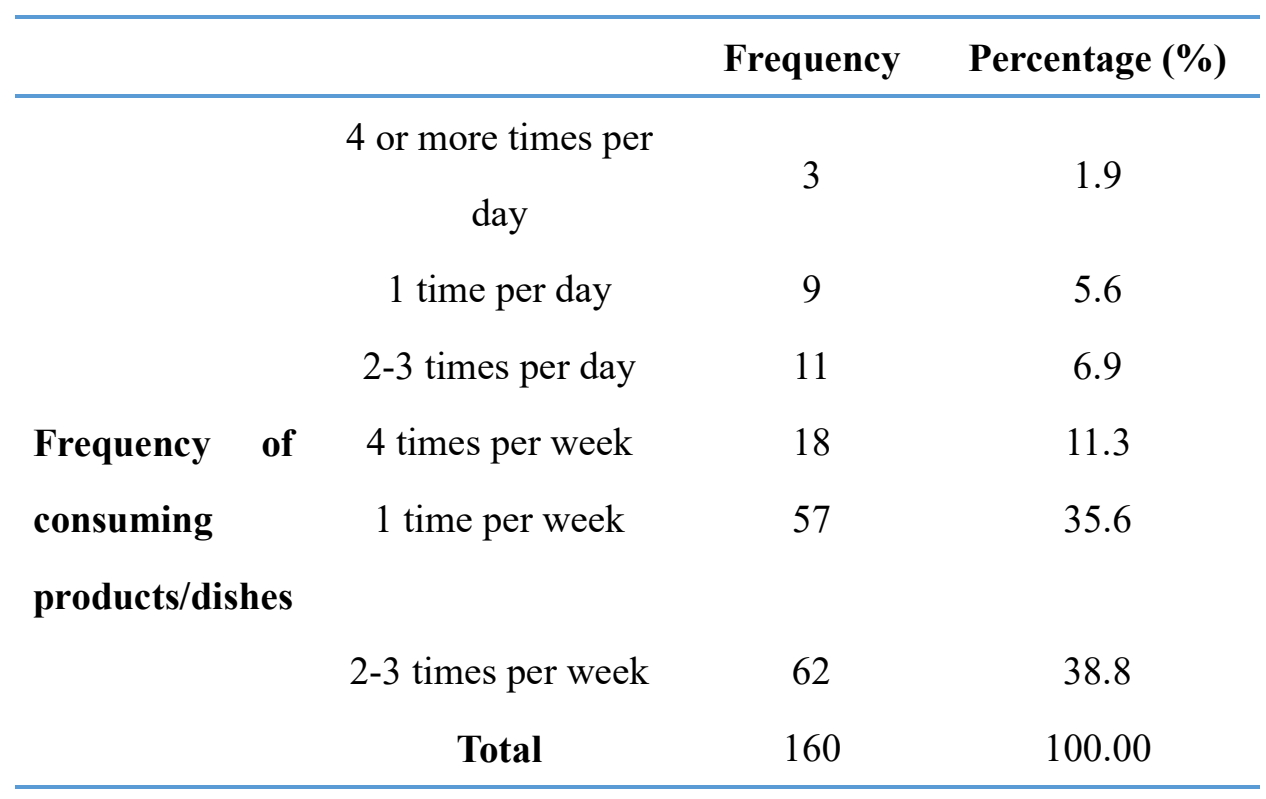


In Table 10 , the result also reveals that majority $(38.8 \% ; n=62)$ of the respondents consume fruit products or dishes 2 to 3 times a week. Then, $35.6 \%(n=57)$ of respondents consume fruit products once a week followed by $11.3 \%(n=18)$ of the respondents consume fruit products four times a week. Other than that, the minority of the respondents consume fruit products 2 to 3 times, once or 4 times per day with the percentages of $6.9 \%(n=11), 5.6 \%(n=9)$ and $1.9 \%$ $(\mathrm{n}=3)$ respectively.

Fruits and vegetables provide various nutrients to our body which can act as a supplement which plays important roles in maintaining a healthy body. They help to maintain a good digestive system, beautiful skin and eyes. Besides, the previous study reported that the consumption of vegetables and fruits leads to a healthy body, and acts as a prevention from critical chronic diseases like diabetes, hypertension, cancer and heart disease [4].

Nevertheless, most of the respondents do not take vegetables and fruits every day. The recommendation for the consumption of vegetables and fruits in Malaysia is five servings (about 400g) per day comprising of two servings of fruits and three serving of vegetables. Hence, majority of the respondents fail to meet the recommended daily intake of fruits and vegetables by the Malaysian Dietary Guidelines 2010. Previous study also reported that Malaysian adults consume fruits in small amount and do not include fruits in their everyday most eaten foods [13]. Besides, this finding is in agreement with Avram \& Oravitan's (2013) finding which showed that two-thirds of the 435 university students from Timisoara University Center are not consuming vegetable or fruit every day [14].

This may be due to the accessibility to unhealthy food choices at university kiosk or cafeteria. It has been reported that there is a lot of unhealthy food choices available in the school setting [4]. It was found that easy access to unhealthy food items results in higher intake of unhealthy foods [15]. This similar situation might have occurred in the university. Nevertheless, this can be lessened by the self-control tactics to encourage healthy consumption of food despite being attracted to unhealthy food [15]. Besides, it was reported that students tend to consume healthy food when it is accessible to them in their nearby surroundings and is free [12]. Therefore, the university is encouraged to provide healthy food choices in the university cafeteria.

If this problem continues to occur, the society will face undesirable health condition in years 
to come. From this study, it is recommended that students develop the desire to consume vegetables and fruits, choose vegetables and fruits with less sugar and sodium, and buy the less costly fruit and vegetable choices. Besides, it is recommended for the respondents to prepare food with fresh vegetables and fruits in various ways using different recipes during meal times and refreshments [16]. Other than that, fruits can usually be eaten as refreshment or desserts after meals. Fruits can also be consumed uncooked regardless of their taste, i.e. sweet, sour or bitter. It is also recommended for students to fill half of their plates with vegetables and fruits and select various types of fruit and vegetable options to gain the optimal benefits of vegetable and fruit consumption.

\subsection{Healthy food innovation awareness based on food groups}

\subsubsection{Vegetables}

According to Fig. 1, this study demonstrates that only $11.2 \%(n=18)$ of respondents answer the question on food innovation. There was a few ideas of innovation suggested, for instance, carrot cake $5.6 \%(\mathrm{n}=9)$ and broccoli fritter $1.3 \%(\mathrm{n}=2)$. Besides, there was also another idea on the innovation of food which is still not available in the market which is cauliflower rice $3.1 \%(n=5)$. There were also other suggestions for food innovation like vegetable cupcake and vegetable candy with the percentage of $0.6 \%(n=1)$ respectively. However, the majority of the respondents, $88.8 \%(n=142)$ did not answer the question, showing that they have little awareness and knowledge of the innovation of food. 


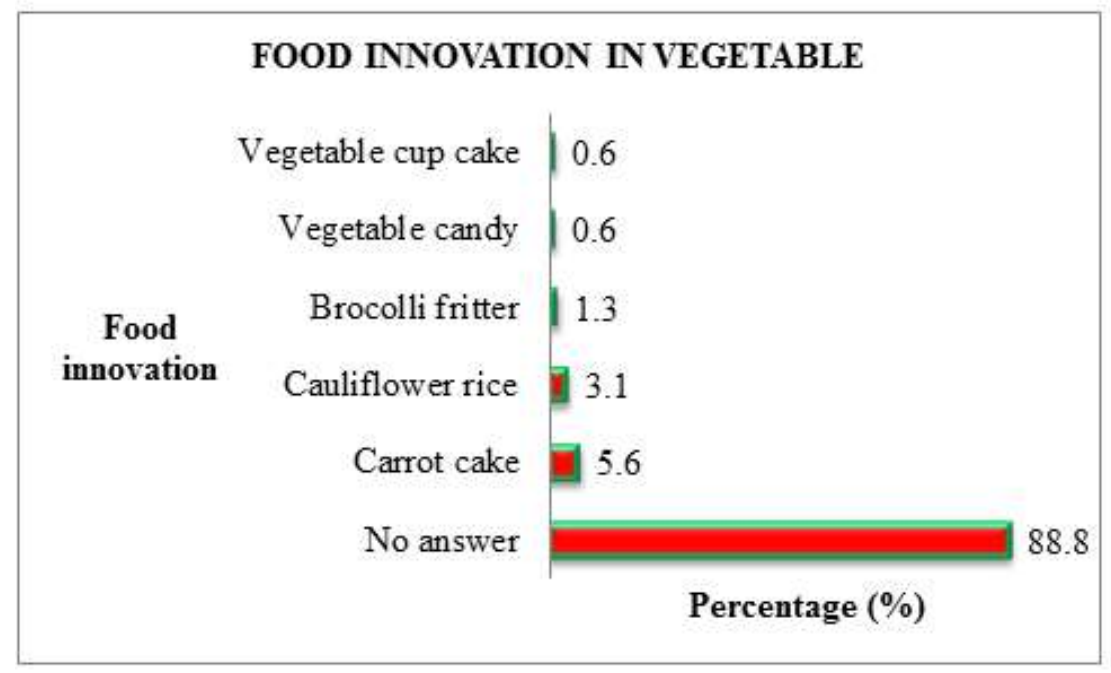

Fig.1. Food innovation in vegetable group

The results demonstrate that only three ideas of vegetable innovations were recommended. This is not surprising due to the little consumption of vegetables, i.e. 2 to 3 times a week among students which proved that they lack knowledge on the options of healthy food innovation. Meanwhile, another alternative that may close the nutrient gap is processed fruits and vegetables which may offer variety thus increasing the consumption of fruits and vegetables [17]. Besides, the methods of cooking such as steaming and poaching instead of frying also play an essential role in determining the right choice of vegetable intake by students.

\subsubsection{Fruits}

As shown in Fig. 2, a majority (78.1\%) of the respondents did not answer the food innovation question in the fruit group while only a small percentage $(21.9 \%)$ of the respondents answered the question. Besides, there were three ideas on fruit innovation suggested by the respondents which are durian crepe $(2.5 \%, \mathrm{n}=4)$, fruit cheesecake $(3.8 \%, \mathrm{n}=6)$ and detox water (i.e lemon mix with cucumber or lime mix with watermelon). $(15.6 \%, n=25)$. The result indicates that the respondents are still not familiar with fruit innovation. This is also related to the low consumption of fruits among respondents. Hence, based on the result, the development of healthier fruit-based food or snack like dried fruit products is recommended. In addition, 
people tend to choose fruits that are organically grown and labelled "Healthy alternative snack" [18].

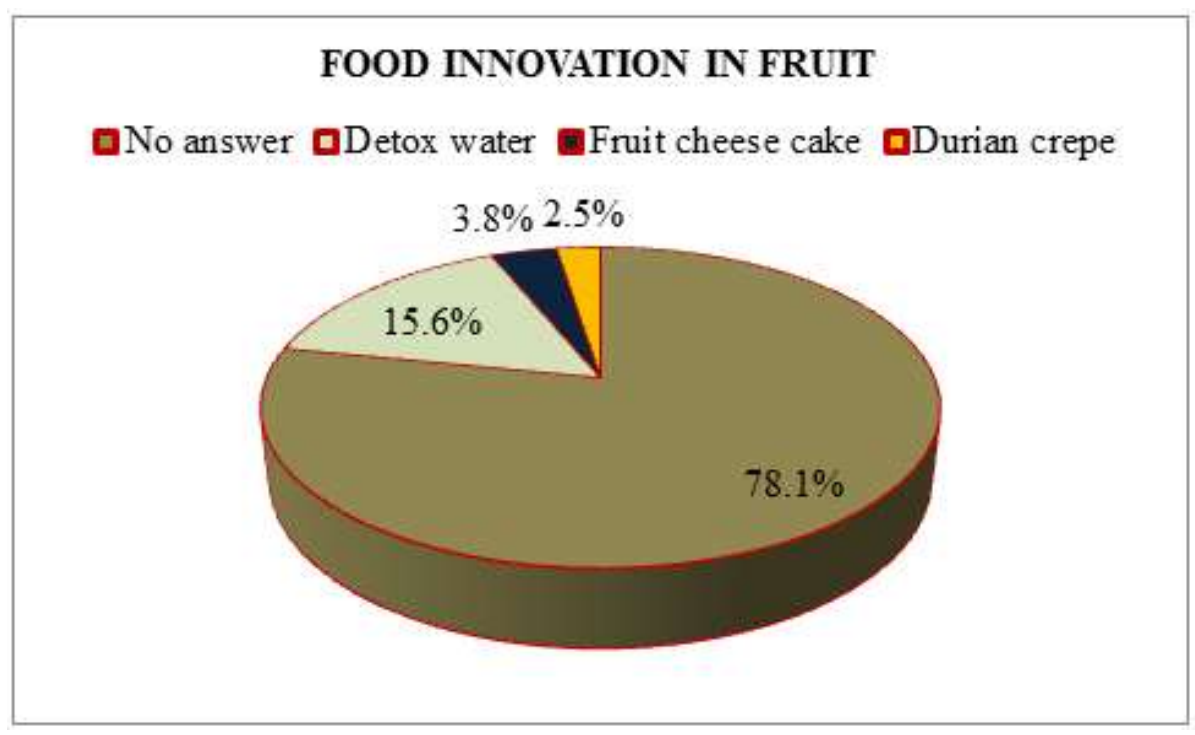

Fig. 2. Food innovation in fruit group

\section{CONCLUSION}

This study has provided a significant and essential information on the preference of vegetables and fruits among young adults aged between 18 to 35 years, especially university students. Different nutritional statuses, genders, and BMI result in different dietary intakes and food preferences. All of the results with the exception of some observations have been supported by the statistical tests performed.

As a result, this study found that most of the respondents consume vegetables 2 to 3 times a week and the most preferred vegetable is kangkung. It is well-known among young adults due to its availability and lower price as compared to other vegetables. Besides, kangkung is a local vegetable preferably chosen by Malaysians due to its soft texture and nice taste. The most preferred vegetable dish is fried kangkung and its availability is high in supermarkets and cafeteria. Meanwhile, the idea of innovation for kangkung is to use it as a condiment in instant foods.

Majority of young adults consumed fruits 2 to 3 times a week with apple being the most preferred fruit. This is because apple is easy to be eaten without the need to be peeled.The 
favourite way of consuming fruit is by drinking fresh juice. Fruit juices are easily found in supermarkets. Meanwhile, the ideas of innovation for apple include apple pasta and apple-flavoured cheese.

In conclusion, majority of the university students do not meet the Malaysian Dietary Guideline recommendations in terms of fruits and vegetable intake. The findings provide some contributions to the knowledge that may help to identify the fruit and vegetable preference among university students which is really important to their health status. The finding is important in helping the development of healthy food products comprising of various food choices based on fruit and vegetable. This concurrently may help to promote healthy lifestyle and healthy eating environment among university students.

\section{ACKNOWLEDGEMENTS}

This research is a collaboration between Universiti Teknologi MARA and Nutrition Centre of Health Department, Dungun, Terengganu, Malaysia. Special thanks for the great support throughout all this study.

\section{REFERENCES}

[1] Drummond K E, Brefere L M. Nutrition for foodservice and culinary professionals $\left(7^{\text {th }}\right.$ eds). New Jersey: John Wiley \& Sons Inc, 2010

[2] Brown K, McIlveen H, Strugnell C. Nutrition and Food Science. 2000, 30 (5), 230-235, doi: https://doi.org/10.1108/00346650010340963

[3] The International Food Information Council. Trends in nutrition, 1988.

[4] HuFB. Plant-based foods and prevention of cardiovascular disease: An overview. Am J Clin Nutr, 2003, 78, 544-551

[5] Al-Naggar R A, Bobryshev Y V, and Noor N A. Asian Pacific Journal of Cancer Prevention. 2013, 14(3),1895-1903, doi:10.7314/APJCP.2013.14.3.1895 •

[6] Sharkawi I, Mohamed Z, and Rezai G. Journal of Economics, Business and Management. 2014, 2(4), 257-261, doi: 10.7763/JOEBM.2014.V2.135

[7] Ministry of Health Malaysia. National health and morbidity survey 2011: Methodology and general findings, 2011 
[8]Ministry of Health Malaysia. National health and morbidity survey 2015: Non-communicable diseases, risk factors and other health problems, 2015.

[9] Morgan E H, Vatucawaqa P, Snowdon W, Worsley A, and Dangour A D. Appetite. 2016, 114-118, doi:http://dx.doi.org/10.1016/j.appet.2016.03.003

[10] He F J, Nowson C A, and MacGregor G A. Lancet. 2006, 367, 320-326, doi: $10.1016 / \mathrm{S} 0140-6736(06) 68069-0$

[11] Ministry of Health Malaysia, Malaysia dietary guidelines, 2010.

[12] Deliens T, Clarys P, Ilse De B, and Deforche B. BMC Public Health. 2014, 14(53), doi:https://doi.org/10.1186/1471-2458-14-53

[13] Norimah A K, Safiah M, Jamal K... Azmi, M Y. Food consumption patterns: Findings from the Malaysian adult nutrition survey. Mal J Nutr, 2008, 14 (1): 25-39

[14] Avram C, Oravitan M. Timisoara Physical Education and Rehabilition Journal. 2013, 5(10), 54-60, doi:10.2478/tperj-2013-0008

[15] Emily de V, John B F, Luszczynska, A, Stok, F M, Gaspar T, Pratt M, Wardle J, Denise T D. European Journal of Public Health. 2013, 23(5), doi: https://doi.org/10. 1093/ eurpub/cks185

[16] Al-Otaibi H H. Psychosocial factors associated with fruit and vegetable consumption among Saudi University Students. Journal of Food and Nutrition. 2014, 1(102), 1-10

[17] Roodenburg A, Leenen R. Trends in Food Science \& Technology. 2007, 18(8), 445-449, doi:10.1016/j.tifs.2006.11.026

[18] Sparke K, Menrad K. Journal of Consumer Marketing. 2011, 28(2), 125-138, doi:10.1108/07363761111115962

[19] Baruch Y, Holtom B C. Human Relations. 2008, 61(8), 1139-1160, doi:10.1177/0018726708094863

[20] Ballantyne C. Moving student evaluation of teaching online: reporting pilot outcomes and issues with afocus on how to increase student response rate. Australasian EvaluationsForum: University Learning and Reaching: Evaluating and Enhancing the Experience, 2005.

[21] Nair CS, Wayland C and SoediroS. Evaluating the student experience: A leap into the future.Australasian Evaluations Forum: University Learning and Teaching:Evaluating and 
Enhancing the Experience, 2005

[22] Cook C, HeathF, and ThompsonR L. A meta-analysis of response rates in web or internet-basedsurveys. Educational and Psychological Measurement, 2000, 60(6): 821-836

[23] Harvard University. Harvard Food Frequency Questionnaire, 2007.

[24] National Institutes of Health, National Cancer Institute. National health and nutrition eximination survey food frequency questionnaire, 2004.

[25] Ministry of Health Malaysia, Malaysian Food Pyramid, 2010.

[26] Nunnally J, Bernstein I H. Psychometric theory ( $3^{\text {rd }}$ ed.). New York: McGraw-Hill, 1994

\section{How to cite this article:}

Mohd Abd Majid H A, Abu Kassim A R, Khalid K, Anuar J, Jusoh N F, Mohd AsriN F S, and AdnanS N S. Fruits and among university vegetables preference students towards developing healthy food innovation products. J. Fundam. Appl. Sci., 2017, 9(5S), 1052-1069. 